\title{
FENOLOGIA COMPARATIVA DE DOIS CLONES ENXERTADOS DE CAJUEIRO ANÃO EM CONDIÇÕES DE IRRIGAÇÃO ${ }^{1}$
}

\author{
COMPARATIVE PHENOLOGY OF TWO GRAFTED CLONES OF DWARF CASHEW \\ TREE IN IRRIGATION CONDITIONS
}

\author{
Francisco Aécio Guedes Almeida ${ }^{2}$, Waldemir Martins Junior ${ }^{3}$, Francisco Célio Guedes Almeida ${ }^{2}$
}

RESUMO

O objetivo do trabalho foi comparar a fenologia de plantas enxertadas dos clones CP 076 e 1001 de cajueiro anão precoce, sob condições de irrigação localizada. O trabalho foi conduzido em uma área experimental da Universidade Federal do Ceará, em Caucaia, Ceará, durante o período de abril de 1985 a março de 1991. As observações foram realizadas em 10 plantas de cada clone contidas em um jardim clonal em um espaçamento de $6 \mathrm{~m} \times 6 \mathrm{~m}$. Foi avaliada a evolução dos crescimentos quantitativo $e$ qualitativo, $d a$ floração $e$ frutificação, da queda foliar e de plantas em produção. As médias mensais de temperatura, umidade relativa do ar, velocidade do vento, e os totais mensais de insolação, de radiação solar e de precipitação pluvial foram determinados durante todo o experimento. Constatou-se que as fenofases altura, envergadura, queda de folhas e crescimento vegetativo qualitativo ocorreram continuamente, para ambos os clones, durante todo o experimento, mais como uma conseqüencia da irrigação a que as plantas foram submetidas. Para as fenofases floração e frutificação, ocorreu uma resposta diferenciada. O clone CP 1001 apresentou uma periodicidade muito mais definida que o clone CP 076. A distribuição das chuvas é o fator meteorológico que parece mais influenciar neste comportamento.

Palavras-chave: Anacardium occidentale L., evolução de fenofases, elementos meteorológicos.

\section{SUMMARY}

The main objective of this research was to compare the phenology of grafted plants of the clones CP 076 and 1001 of precocious dwarf cashew tree, under localized irrigation conditions. It was carried out from April 1985 to March 1991 on an experimental area of the Federal University of Ceará, in Caucaia, Ceará, Brazil. Observations were taken on 10 plants from each clone planted in a clonal germoplasm area spaced $6 \mathrm{~m}$ $x 6 \mathrm{~m}$. The development of quantitative and qualitative growths, leaves abscission, flowering, fruit set, and plants in production were evaluated The monthly averages of temperature, relative humidity of air, and wind speed as well as the monthly totals of insolation, solar radiation, and rainfall were registered during the whole experiment. It was verified that height, plant spread, leaves abscission, and qualitative vegetative growth took place for both clones, continuously throughout the experiment, more as a consequence of the irrigation that the plants were submitted. Flowering and fruit set of both clones showed a different behaviour. The clone CP 1001 presented a much more defined periodicity than clone CP 076. The rain distribution is the climatic factor that seems to influence more in this behaviour.

Key words: Anacardium occidentale L., phenophases development, meteorological data.

\section{INTRODUÇÃO}

As espécies vegetais não obedecem a uma estratégia comum de controle, mas, geralmente são influenciadas por um tipo de mecanismo básico que pode ser considerado como uma resposta integrada a fatores ambientais (exógenos), os quais através da influência sobre processos fisiológicos (endógenos) da planta contribuem variadamente para a brotação de gemas, crescimento e floração (HUXLEY \& VAN ECK, 1974).

\footnotetext{
${ }^{1}$ Parte do trabalho de dissertação de mestrado "Fenologia e ecologia comparativas da produtividade de dois clones de cajueiro anão precoce (Anacardium occidentale L.), sob condições de irrigação localizada, submetida à coordenação do Curso de Pós-graduação em Fitotecnia da Universidade Federal do Ceará, em Fortaleza-Ce", defendida em abril de 1993.

${ }^{2}$ Engenheiro Agrônomo, PhD., Professor da Universidade Federal do Ceará. Rua Osvaldo Cruz, 250/400, Meireles, 60125-150, Fortaleza, Ceará, Brasil.

${ }^{3}$ Engenheiro Agrônomo, M.Sc.
} 
O crescimento e desenvolvimento do cajueiro são influenciados, principalmente, pela disponibilidade de água e radiação solar (PARENTE, 1981). O cajueiro caracteriza-se por apresentar crescimento intermitente cuja periodicidade pode manifestar-se em diferentes níveis de intensidade de fluxo foliar. A planta apresenta uma aparente fase de repouso vegetativo de janeiro a abril que coincide com o período de maior concentração de chuvas (FROTA, 1988). Uma renovação vegetativa de grande intensidade é, normalmente, observada a partir de junho, e, também, logo após o período de maiores precipitações pluviais. A outra renovação vegetativa, pouco expressiva, ocorre freqüentemente em novembro, após as chuvas esparsas, comuns nesse período do ano.

ALMEIDA et al. (1995a), trabalhando com progênies dos clones CP 076 e 1001, em condições de irrigação com água $\mathrm{C}_{3} \mathrm{~S}_{1}$ - altamente salina e não sódica, em um solo argissolo vermelho amarelo, observaram que o crescimento tanto da altura como da envergadura de ambas as progênies ocorreu de forma contínua, sendo que a 1001 desenvolveu-se mais, atingindo na estabilização, no sexto ano de vida da planta, $5,05 \mathrm{~m}$ de altura e $7,9 \mathrm{~m}$ de envergadura média, enquanto a 076 alcançou $4,73 \mathrm{~m}$ de altura e 7,1m de envergadura média. A renovação foliar aconteceu continuamente para ambas as progênies durante todo o experimento. As fenofases floração e frutificação ocorreram com maior intensidade no período de estiagem, de junho a novembro, em cada ano pesquisado, destacando que as variações das condições meteorológicas podem alterar, de certo modo, referidas fenofases. ALMEIDA et al. (1995b), trabalhando com plantas enxertadas, cultivadas em uma areia quartzosa, também irrigadas, mas com água $\mathrm{C}_{2} \mathrm{~S}_{1}$ - pouco salina e não sódica, demonstraram que a umidade relativa do ar e a precipitação pluvial foram os elementos meteorológicos que mais influenciaram as fenofases vegetativas e reprodutivas estudadas. Eles acrescentaram que a estabilização do crescimento, em altura e em envergadura, deu-se no sexto ano de vida das plantas, alcançando, em média, 3,5m em altura e $7,8 \mathrm{~m}$ em envergadura. $\mathrm{O}$ crescimento das plantas em envergadura, contudo, só ultrapassou o crescimento em altura após as mesmas completarem um ano de vida no campo. A fenofase queda de folhas só se iniciou no final do primeiro ano de vida das plantas no campo, não sofrendo solução de continuidade até o término do experimento. A floração e frutificação iniciaram-se no primeiro ano de vida das plantas, mantendo-se, também, ao longo de todo o período experimental.

FROTA (1988) afirma que a queda de folhas do cajueiro ocorre durante todo $\mathrm{o}$ ano, aumentando, acentuadamente, a partir de maio, logo após as precipitações pluviais mais intensas, e, atingindo o pico entre junho e agosto. Este pico incide, freqüientemente, com o período da mais intensa brotação de gemas. ALMEIDA (1982) e ALMEIDA \& MARTINS JÚNIOR (1984) citam que, embora se observe a queda foliar ao longo de todo o ano (queda lenta), esta só se intensifica aproximadamente um mês após o pico de precipitação pluvial observado nos seis meses da estação chuvosa. É importante salientar que essa fenofase sempre é seguida pelo novo crescimento ativo da planta.

O florescimento do cajueiro varia de 5 a 7 meses e a época depende do período de distribuição das precipitações pluviais, observando-se, no entanto, uma grande variação para o período de florescimento, sendo possível encontrar planta que floresce durante o ano inteiro e planta que apresenta um período mais concentrado de floração (BARROS, 1988). A floração ocorre sempre durante a estação seca em que predomina pouca nebulosidade e alta insolação. A distribuição da floração no cajueiro é, visivelmente, dependente de crescimento vegetativo (FROTA, 1988).

Conforme PARENTE (1981), o cajueiro anão se caracteriza por iniciar seu crescimento mais cedo na estação e por apresentar porte reduzido, entre outras características. BARROS et al. (1984) afirmam que as melhores condições para o desenvolvimento do cajueiro são encontradas em regiões com precipitação pluvial anual entre 800 a $1600 \mathrm{~mm}$, porém, de acordo com EPABA (1984), com uma estiagem acentuada de 3 a 4 meses, no período de florescimento e frutificação. A umidade relativa ideal para o desenvolvimento da cultura do caju situa-se em torno de 65\% (MEDINA, 1978). FEITOSA \& FEITOSA (1971) afirmam que o cajueiro apresenta um ótimo desenvolvimento entre 70 e $80 \%$ de umidade relativa. Citam, também, que a temperatura ótima para o desenvolvimento e frutificação normais está compreendida entre os limites de 22 a $32^{\circ} \mathrm{C}$. Para FROTA (1988), o vento funciona como importante agente polinizador do cajueiro, uma vez que a cultura apresenta alta taxa de polinização cruzada. Porém, PARENTE et al. (1972) cita que o vento, quando muito intenso, pode determinar a queda das flores e dos frutos no seu estágio inicial de desenvolvimento. AGNOLONI \& GIULIANI (1977) dimensionam essa intensidade afirmando que ventos superiores a $7 \mathrm{~m} / \mathrm{s}$ prejudicam a cultura.

ALMEIDA (1982) e ALMEIDA (1988) afirmam que o crescimento vegetativo, tanto qualitativo como quantitativo, ocorreram durante todos os meses dos períodos em que suas pesquisas 
foram realizadas. Este crescimento vegetativo continuado, estimulado pela irrigação localizada e controlada na estação seca, conduziu ao desenvolvimento reprodutivo, também, continuado por todo o período experimental.

De acordo com BARROS et al. (1984), a frutificação no cajueiro anão ocorre na estação seca. No Ceará, a duração do período de frutificação é mais longa, e, em anos de precipitação pluvial favorável, a frutificação pode iniciar-se em julho, estendendo-se até fevereiro. Porém, a maior intensidade de frutificação ocorre no período de setembro a novembro.

Esse trabalho teve como objetivo comparar a fenologia de plantas enxertadas dos clones CP 076 e 1001 de cajueiro anão (Anacardium occidentale $\mathbf{L}$.), ao longo dos seus seis primeiros anos de cultivo, em condições de irrigação, especialmente, para oferecer subsídios para plantios futuros em explorações racionais.

\section{MATERIAL E MÉTODOS}

Esse trabalho foi realizado durante o período de abril de 1985 a março de 1991, em uma área localizada na Fazenda Garrote, em Caucaia - Ceará, a $18 \mathrm{~km}$ de Fortaleza, a $3^{\circ} 41^{\prime}$ de latitude $\mathrm{S}$ e $35^{\circ} 43^{\prime}$ de longitude $\mathrm{W}$, ao nível do mar. A área é representativa do litoral leste do estado, onde predomina a formação caatinga hipoxerófila. O solo é uma areia quartzosa distrófica e seu relevo é plano. De acordo com dados climáticos registrados por uma estação localizada em Fortaleza, a $18 \mathrm{~km}$ da área de pesquisa, durante o período de 1966 a 1995, a temperatura do ar na região varia de 23,5 a $30,2^{\circ} \mathrm{C}$, com uma temperatura média de $26,7^{\circ} \mathrm{C}$. Observa-se, na área, a existência de duas estações bem definidas: (a) uma chuvosa, de janeiro a julho, quando se concentram $92,32 \%$ das precipitações pluviais, com picos nos anos normais, em março e abril, e (b) uma seca, de agosto a dezembro, com chuvas esporádicas de formação local que, dificilmente, ultrapassam os $40 \mathrm{~mm}$ mensais. A precipitação pluvial anual média é de $1.642 \mathrm{~mm}$, e a umidade relativa anual média é de $79 \%$. A velocidade média do vento é de $3,9 \mathrm{~m} / \mathrm{s}$, variando durante o ano de $2,6 \mathrm{~m} / \mathrm{s}$, em abril, a 5,2m/s em setembro. Já a insolação anual média é de 2.766 horas, e a radiação anual média é de $147.592 \mathrm{ca} \ell / \mathrm{cm}^{2}$ (UNIVERSIDADE FEDERAL DO CEARÁ, 1997).

O sistema de irrigação usado foi o de jato pulsante, sendo os jatos espaçados a intervalos de tempo de 16 a 22 pulsações por minuto. A água empregada na irrigação pertence à classe $\mathrm{C}_{2} \mathrm{~S}_{1}$ - água com salinidade média e com baixo teor de sódio, conforme a classificação do Laboratório de Salinidade dos Estados Unidos da América (RICHARDS, 1954). A quantidade média de água aplicada por planta/dia, tanto nos dias secos da estação chuvosa como na estação seca, foi de 9, 15, 21, 27, 33 e 40 litros, nos primeiro, segundo, terceiro, quarto, quinto e sexto anos, respectivamente.

Devido as suas características físicas e químicas, o solo da área experimental é classificado como uma areia quartzosa. Apresenta $\mathrm{pH}$ de 5,8, baixa fertilidade, principalmente em termos de fósforo e potássio, e baixa retenção d'água.

As observações foram realizadas em 10 plantas enxertadas do clone $\mathrm{CP} 76$ e 10 do clone $\mathrm{CP}$ 1001, selecionadas aleatoriamente em um jardim clonal mantido na área experimental acima relacionada. O transplantio ocorreu em abril de 1985 e foi realizado em covas de $0,40 \mathrm{~m} \times 0,40 \mathrm{~m} \times 0,40 \mathrm{~m}$, adubadas com 10 litros de esterco de gado bovino bem curtido. $\mathrm{O}$ plantio obedeceu a um espaçamento de $6 \mathrm{~m} \times 6 \mathrm{~m}$.

Após três meses da implantação da cultura, quando ficou evidenciada a estabilização das plantas no lugar definitivo, passou-se a realizar as seguintes observações: (1) altura da planta (ALT), determinada a cada três meses, medindo-se a partir da superfície do solo até o ápice da envergadura; (2) envergadura da copa (ENV), registrada a cada três meses, estabelecida pela média aritmética dos diâmetros Norte-Sul e Leste-Oeste da copa; (3) queda de folhas (PQF) que constou do registro mensal de folhas amarelas e/ou secas acumuladas na área de projeção da envergadura das plantas; (4) crescimento vegetativo qualitativo $(\mathrm{PCV})$, avaliado mensalmente, de acordo com a presença de folhas marronavermelhadas, as quais são características de um novo crescimento vegetativo da planta; (5) floração (PFL), registrada em seu início e em sua conseqüente manutenção durante o ano agrícola, e, (6) frutificação (PFR), igualmente a floração, observada em seu início e em sua permanência durante o ano agrícola. As quatro últimas variáveis foram determinadas em termos de percentagem de plantas que expressavam o relacionado evento.

Os dados meteorológicos registrados durante os seis anos da pesquisa foram a temperatura, umidade relativa do ar, velocidade do vento, insolação, radiação solar e precipitação pluvial. Este último elemento foi registrado no próprio local do experimento através de um pluviômetro instalado na área de estudo. O restante dos elementos meteorológicos foi registrado pela Estação de Meteorologia do Centro de Ciências Agrárias da Universidade Federal do Ceará. Esta estação situa-se em uma posição geográfica semelhante àquela ocupada pela área experimental. 
Os dados obtidos para cada uma das fenofases estudadas em cada clone foram correlacionados com as variáveis meteorológicas acima mencionadas, avaliando-se as diferenças entre clones pelas diferenças dos valores dos coeficientes determinados.

\section{RESULTADOS E DISCUSSÃO}

A síntese dos dados meteorológicos está apresentada na tabela 1 . O regime pluviométrico do período 1985/1991 seguiu o modelo da região definido pelas normais de pluviosidade - 1966/1995, conforme UNIVERSIDADE FEDERAL DO CEARÁ (1997), distinguindo-se, claramente, duas estações: uma chuvosa na primeira metade do ano, seguida de outra seca - correspondendo à segunda metade do ano. Normalmente, a estação chuvosa inicia-se em janeiro, estendendo-se até julho, e a seca que ocorre de agosto a dezembro, embora variações na quantidade e distribuição de chuvas sejam evidentes entre os anos estudados.

A altura ou crescimento vegetativo vertical ocorreu de maneira contínua em ambos os clones pesquisados, durante todo o período experimental (Figura 1). O clone CP 1001 passou a apresentar uma maior altura a partir do $12^{\circ}$ mês da implantação do experimento, atingindo na estabilização, aos seis anos de idade, uma altura média de $4,15 \mathrm{~m}$, enquanto o clone CP 076 atingiu nessa idade, uma altura de 3,3m.

A envergadura ou crescimento vegetativo lateral de ambos os clones desenvolveu-se de maneira contínua durante todo o experimento (Figura 1), corroborando com os resultados obtidos por ALMEIDA et al. (1995a), que trabalhou com progênies desses dois clones considerados. Logo no $9^{\circ}$ mês após o plantio, a altura do clone $\mathrm{CP} 076$ foi superada pela envergadura, enquanto o clone CP 1001 só apresentou este comportamento cinco meses depois. Progênies originadas desses clones, ainda, conforme ALMEIDA et al., (1995a), demonstraram esta mesma característica nove meses após o plantio no campo. O clone CP 1001, contudo, passou a apresentar uma maior envergadura que o clone $\mathrm{CP} 076$ a partir do $22^{\circ}$ mês de implantação do experimento. $\mathrm{Na}$ estabilização do crescimento, aos seis anos de idade das plantas, enquanto o clone CP 076 alcançou uma envergadura média de 7,75m, o clone CP 1001 atingiu 8,5m, representando mais do que o dobro de suas alturas para ambos os clones. Destaca-se que o tempo de vida que a planta leva, no campo, para apresentar a envergadura superior à altura parece ser mais um indicativo de nanismo e, também, de precocidade, característica mais compatível com o clone CP 076.

Determinando-se o coeficiente de correlação entre os elementos meteorológicos e o crescimento em altura e em envergadura de ambos os clones, constatou-se uma tendência de influência positiva da temperatura média compensada e uma tendência de correlação negativa dos elementos umidade relativa do ar, insolação e radiação solar, embora tais correlações sejam mínimas na maioria dos anos (Tabela 2). Já com relação à precipitação pluvial e a velocidade do vento, essas tendências não ficaram claramente definidas.

O início da queda de folhas velhas coincidiu com a época em que as plantas interromperam $\mathrm{O}$ seu crescimento vegetativo qualitativo, isto é, quando deixaram de emitir novos brotos, momento em que se iniciou a renovação foliar nos dois clones, em 04/86 13 meses após o transplantio. Muito embora a queda de folhas velhas tenha começado ao mesmo tempo em ambos os clones, a intensidade com que isso ocorreu não foi a mesma. Nesse momento, $50 \%$ das plantas do clone CP 076 iniciaram a queda de folhas, alcançando os $100 \%$ em junho de 1986. De julho a dezembro de 1986, esta fenofase para este clone 


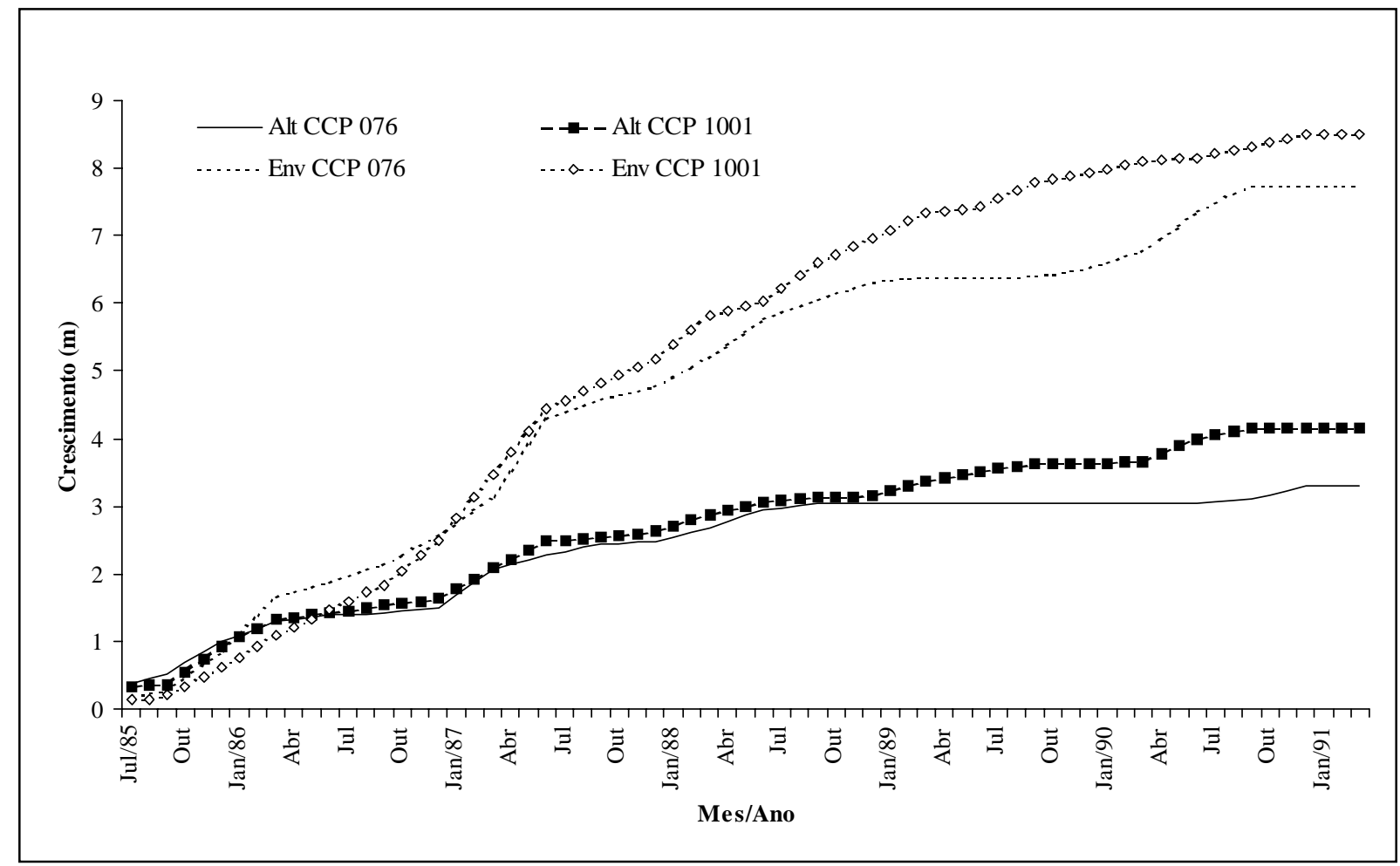

Figura 1. Evolução comparativa da altura e envergadura de plantas enxertadas de dois clones de cajueiro anão precoce, em condições de irrigação, em Caucaia, Ceará.

oscilou de 50 a $100 \%$. A partir de dezembro de 1986 , $100 \%$ das plantas apresentaram queda de folhas velhas até o final do experimento. No clone CP 1001, a queda de folhas começou em $75 \%$ de suas plantas. Somente em $7 / 86$, detectou-se taxa de $100 \%$ de suas plantas com esta fenofase, caindo tal índice no mês seguinte para $50 \%$. Este clone somente apresentou taxas estabilizadas ao nível de $100 \%$ de queda de folhas, em dezembro de 1986, a exceção, do mês fevereiro de 1990 quando se registrou $75 \%$ das plantas com essa fenofase. A resposta ligeiramente diferenciada de ambos os clones para o início e a estabilização ao nível de $100 \%$ na queda de folhas velhas, pode ser atribuído a fatores genéticos, pois a análise estatística não evidenciou nenhuma correlação entre esta fenofase e os elementos meteorológicos estudados. Como o clone CP 076 foi sempre mais precoce, sazonalmente, que o clone $\mathrm{CP}$ 1001, mesmo submetidos às mesmas condições ecológicas, pode-se inferir que essa precocidade se deve a uma diferença genética entre ambos.

A fenofase crescimento vegetativo qualitativo ocorreu simultaneamente em ambos os clones, porém, a intensidade com que se verificou não foi a mesma. No clone CP 076, foram observadas grandes oscilações na taxa de emissão de rebrotos até o $21^{\circ}$ mês após o transplantio, em dezembro de 1986, momento em que alcançou a estabilização ao nível de $100 \%$ das plantas. O clone CP 1001, por sua vez, apresentou menores oscilações em suas taxas de emissão de novos rebrotos. O referido clone, porém, só apresentou taxas estabilizadas ao nível de $100 \%$, em setembro de 1986, portanto, no $18^{\circ}$ mês após o transplantio, mantendo essa taxa até o final do experimento.

As respostas diferenciadas entre os clones estudados para alcançar a taxa máxima e contínua no seu crescimento vegetativo qualitativo podem ser explicadas devido a fatores genéticos, uma vez que não existiu correlação entre esse evento periódico e os elementos meteorológicos, conforme foi constatado através de cálculos estatísticos.

A taxa de $100 \%$ de crescimento vegetativo qualitativo, desses clones, durante quase todo o experimento, e a não existência de correlação entre os dados meteorológicos e esse tipo de crescimento, contraria o modelo de crescimento vegetativo sugerido para o cajueiro em condições de sequeiro por alguns autores, entre os quais DASARATHI (1958), NAMBIAR (1975) e PARENTE (1981). Esta resposta pode ser explicada, pelo fato de que, durante todo o experimento, as plantas foram irrigadas nos

Ciência Rural, v. 32, n. 2, 2002. 
Tabela 2 - Correlação entre variáveis meteorológicas e a altura e envergadura de plantas enxertadas dos clones CP 076 e 1001 de cajueiro anão precoce, em condições de irrigação, em Caucaia, Ceará.

\begin{tabular}{|c|c|c|c|c|c|c|c|c|}
\hline \multirow[t]{3}{*}{ Período } & \multicolumn{2}{|c|}{ Altura } & \multicolumn{2}{|c|}{ Envergadura } & \multicolumn{2}{|c|}{ Altura } & \multicolumn{2}{|c|}{ Envergadura } \\
\hline & CP 076 & CP 1001 & CP 076 & CP 1001 & CP 076 & CP 1001 & CP 076 & CP 1001 \\
\hline & \multicolumn{4}{|c|}{ Temperatura média compensada } & \multicolumn{3}{|c|}{ Umidade relativa do ar } & \\
\hline $1985 / 86$ & 0,564 & 0,473 & 0,357 & 0,385 & 0,274 & 0,409 & 0,474 & $-0,458$ \\
\hline $1986 / 87$ & $0,613^{*}$ & $0,736^{*}$ & $0,874^{*}$ & $0,862 *$ & 0,137 & $-0,082$ & $-0,278$ & $-0,247$ \\
\hline $1987 / 88$ & 0,291 & 0,441 & 0,452 & 0,493 & $-0,287$ & $-0,217$ & $-0,373$ & $-0,388$ \\
\hline $1988 / 89$ & 0,537 & 0,451 & 0,708 & $0,766^{*}$ & $-0,378$ & $-0,113$ & $-0,250$ & $-0,390$ \\
\hline $1989 / 90$ & $0,616^{*}$ & $0,641 *$ & 0,767 & $0,820^{*}$ & $-0,962 *$ & $-0,941 *$ & $-0,648 *$ & $-0,837 *$ \\
\hline \multirow[t]{2}{*}{$1990 / 91$} & 0,454 & $-0,050$ & 0,050 & 0,376 & $-0,324$ & $-0,437$ & $-0,437$ & $-0,356$ \\
\hline & \multicolumn{4}{|l|}{ Insolação } & \multicolumn{2}{|c|}{ Radiação solar } & & \\
\hline $1985 / 86$ & $-0,448$ & $-0,572$ & $-0,625^{*}$ & $-0,613 *$ & $-0,234$ & $-0,368$ & $-0,442$ & $-0,424$ \\
\hline $1986 / 87$ & $-0,496$ & $-0,321$ & $-0,167$ & $-0,198$ & $-0,290$ & $-0,095$ & 0,081 & 0,048 \\
\hline $1987 / 88$ & $-0,494$ & $-0,671 *$ & $-0,504$ & $-0,512$ & $-0,132$ & $-0,245$ & $-0,070$ & $-0,061$ \\
\hline $1988 / 89$ & 0,385 & 0,110 & 0,366 & 0,520 & $-0,237$ & $-0,498$ & $-0,279$ & $-0,109$ \\
\hline $1989 / 90$ & $0,940 *$ & $0,905^{*}$ & 0,203 & $0,631 *$ & 0,400 & 0,433 & $0,743 *$ & $0,677 *$ \\
\hline $1990 / 91$ & $-0,385$ & $-0,095$ & $-0,095$ & $-0,344$ & $-0,323$ & 0,279 & 0,279 & $-0,222$ \\
\hline
\end{tabular}

*Significativo ao nível de $5 \%$ de probabilidade pelo teste Tukey. Valores de $\mathbf{r}$ menores que 0,001 foram considerados como 0,0 .

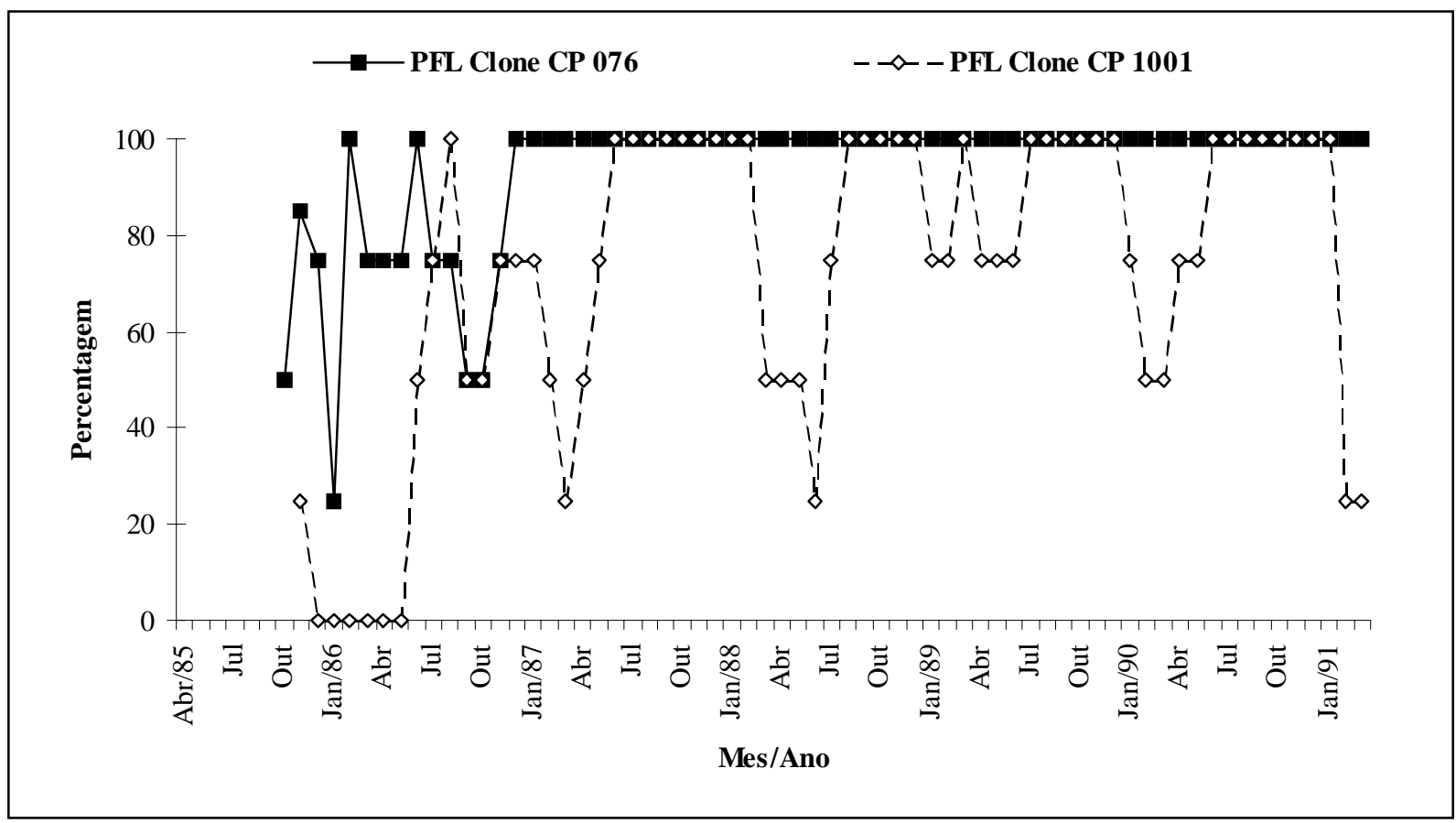

Figura 2. Evolução comparativa da floração de plantas enxertadas de dois clones de cajueiro anão em condições de irrigação, em Caucaia, Ceará.

períodos de estiagem e de baixa precipitação pluvial. Além disso, os demais elementos meteorológicos da região mantiveram-se quase sempre em uma faixa ideal para o desenvolvimento da cultura.

Conforme pode ser visualizado nas figuras 2 e 3, as fenofases floração e frutificação apresentaram algumas diferenças entre as plantas dos dois clones. O CCP 076 foi mais precoce, iniciando sua floração um mês antes do CCP 1001, outubro e novembro de 1985, respectivamente. Após o seu início, a manutenção da floração no clone CP 076, nos seis anos da pesquisa, mostrou-se contínua e, quase sempre, em um maior número de plantas do que no clone CP 1001. Esse evento, neste clone,

Ciência Rural, v. 32, n. 2, 2002. 


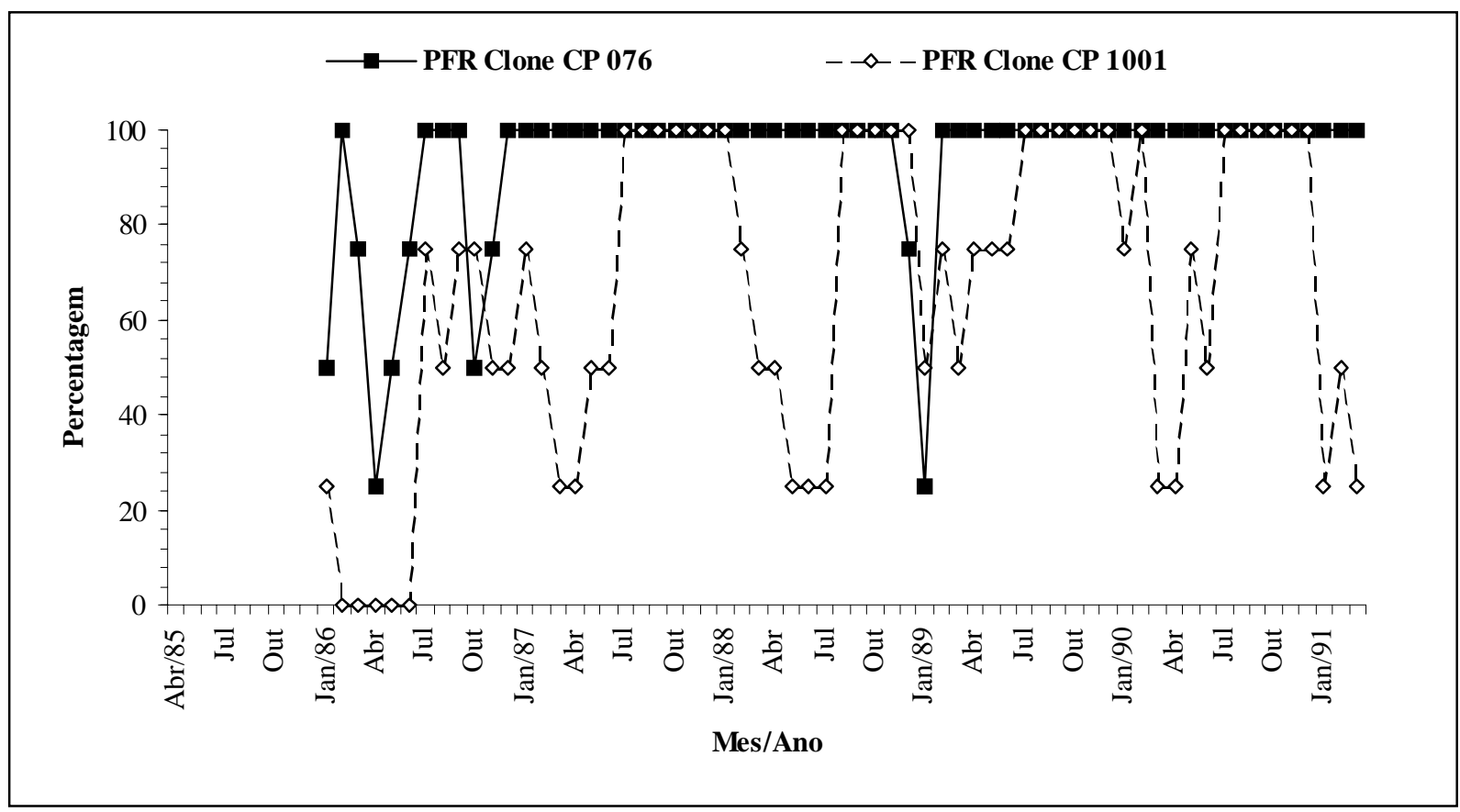

Figura 3. Evolução comparativa da frutificação de plantas enxertadas de dois clones de cajueiro anão em condições de irrigação, em Caucaia, Ceará.

mostrou-se descontinuado durante seis meses nos dois primeiros anos de vida das plantas. A frutificação dos dois clones, por outro lado, teve início na mesma época, em janeiro de 1986, mantendo-se, no clone CP 076, contínua até o final do experimento, sendo as plantas do clone CP 1001 muito sensíveis às variações de precipitação pluvial e de umidade relativa do ar. Para corroborar esta afirmação, foram cruzados os dados meteorológicos mensais com as taxas de plantas em floração e frutificação de ambos os clones, o que ficou constatado uma tendência de correlação significativa entre a precipitação pluvial e a umidade relativa do ar com essas fenofases somente para o clone CP 1001 (Tabela 3).

As plantas de ambos os clones iniciaram sua produção concomitantemente com o início da frutificação, em janeiro de 1986, divergindo no percentual, isto é, $50 \%$ no clone CP 076 e $25 \%$ no clone CP 1001, confirmando, assim, ser o clone CP 1001 mais tardio que o 076. Outra diferença refere-se à continuidade da produção, o clone $\mathrm{CP}$ 076, após ter iniciado sua produção em fevereiro de 1986, somente deixou de registrar esta fenofase em abril do mesmo ano. O clone CP 1001 apresentou uma produção com tendência a sazonalidade, demonstrando ser mais sensível às precipitações pluviais que o clone CP 076. As plantas do clone CP 1001 nos meses de altas precipitações pluviais sempre apresentaram um percentual de plantas em produção menor do que aquele mostrado para o clone CP 076. A correlação entre a precipitação pluvial e a fenofase produção apresentou uma clara tendência de correlação negativa para as plantas do clone CP 1001, não evidenciando uma tendência definida de correlação para o clone CP 076. Já em relação

* Significativo ao nível de $5 \%$ de probabilidade pelo teste Tukey. Valores de $\mathbf{r}$ menores que 0,001 foram considerados como 0,0 .

Ciência Rural, v. 32, n. 2, 2002. 
ao elemento meteorológico umidade relativa do ar, existe nítida tendência de correlação negativa para ambos os clones, sendo que esta correlação negativa é muito mais intensa para o clone CP 1001.

A resposta das plantas de ambos os clones, no tocante à fenofase produção, vem corroborar com as interpretações anteriores para as fenofases floração e frutificação, existindo uma tendência do clone $\mathrm{CP}$ 1001 ser mais tardio que o 076, sendo, também, mais sensível à elevação nas taxas de precipitação pluvial e umidade relativa do ar.

\section{CONCLUSÕES}

$\mathrm{O}$ crescimento em altura e em envergadura da copa ocorre continuamente para os clones CP 076 e 1001, sendo que o 076 foi maior em altura no primeiro ano e em envergadura nos dois primeiros anos.

As plantas do clone CP 1001, apresentando uma envergadura de copa bem maior que a envergadura de copa das plantas do clone CP 076, mostram a necessidade de um maior espaçamento entre plantas.

A estabilização da altura e da envergadura de ambos os clones ocorre no seu sexto ano de vida.

A queda e renovação foliar ocorrem continuamente, durante praticamente todo o período experimental, mostrando os mesmos índices para ambos os clones.

As plantas do clone CP 076 são mais precoces, tanto para a floração como para a frutificação.

\section{REFERÊNCIAS BIBLIOGRÁFICAS}

AGNOLONI, M., GIULIANI, F. Cashew cultivation. Firenze : Inst. Agronomico per L'Oltremare, 1977. 168p.

ALMEIDA, F.A.G. Estudos fenológicos do cajueiro (Anacardium occidentale L.) em Fortaleza. Fortaleza : UFC/CNPq. 1982. 17p. (Relatório Técnico, s.n.).

ALMEIDA, F.A.G., MARTINS JR., W. Estudos fenológicos do cajueiro (Anacardium occidentale L.) em áreas do litoral cearense, Fortaleza, CE, 1984. In: ENCONTRO NACIONAL DA AGROINDÚSTRIA DO CAJU,1 SEMANA CEARENSE DO CAJU, 2, 1984, Fortaleza, Ceará. Anais... Fortaleza : Governo do estado do Ceará/Embrapa/Secretaria de Agric. e Abast. do Ceará/EPACE, 1984. p.25-26.

ALMEIDA, F.A.G. Estudos fenológicos e de produtividade do cajueiro anão (Anacardium occidentale $\mathrm{L}$.) sob condições de irrigação localizada. Fortaleza : UFC/CNPq, 1988. 40p. (Relatório Técnico)

ALMEIDA, F.A.G., ALMEIDA, F.C.G., NUNES, R. de P., $\boldsymbol{e t}$ al Estudos fenológicos de plantas enxertadas de cajueiro anão sob condições de irrigação. Rev Bras. de Fruticultura, Cruz das Almas, v.17, n.2: p.71 - 84, 1995a.
ALMEIDA, F.A.G., SILVA, A.Z., ALMEIDA, F.C.G., $\boldsymbol{e t}$ al. Fenologia comparativa de duas progênies de cajueiro anão sob condições de irrigação. Rev de la Fac de Agronomía, Maracay, Venezuela, v.21, n.3-4: p.157 - 178, 1995 b.

BARROS, L. DE M., ARAÚJO, F.E. de, ALMEIDA, J. I. L. de., et al. A cultura do cajueiro anão. Fortaleza : Empresa de Pesquisa Agropecuária do Ceará - EPACE, 1984. 67p.

BARROS, L. de M. Biologia foral, colheita e rendimento. In: LIMA, V.P.M.S. A cultura do cajueiro no Nordeste do Brasil. Fortaleza : BNB/ETENE, 1988. Cap.12. p.323 - 325.

DASARATHI, T.B. A study of the blossom biology and growth features of cashew-nut (Anacardium occidentale $\mathbf{L}$.). Waltair, INDIA, 1958. 110 p. Dissertação (Mestrado em Agronomia) - Curso de Pós-graduação em Agronomia, Andhra University, 1958.

EPABA. Introduções práticas para o cultivo de frutos tropicais. Salvador : EPABA, 1984. s.p. (Circular Técnica, 9).

FEITOSA, J.C., FEITOSA, D.A. Síntese global dos trabalhos apresentados na $1^{\text {a }}$ Semana do Caju. Fortaleza : Federação da Agricultura do Estado do Ceará, 1971. 101p.

FROTA, P.C.E. Clima e fenologia. In: LIMA, V.P.M.S. A cultura do cajueiro no Nordeste do Brasil. Fortaleza : BNB/ETENE, 1988. Cap.3. p.63-80.

HUXLEY, P.A., VAN ECK, W.A. Seasonal changes in growth and development of some woody perennial plants near Kampala. J Ecol, Uganda, v.62, p.579-592, 1974.

MEDINA, J.C. Cultura do cajueiro. In: MEDINA, J.C.; BLEINTOTH, E.W.; BERNHARDT, L.W. Caju: da cultura ao processamento e comercialização. Campinas: Instituto de Tecnologia de Alimentos, 1978. p.5-66. (INSTITUTO DE TECNOLOGIA DE ALIMENTOS. Série Frutas Tropicais, 4).

NAMBIAR, M.C. Ecophysiology of cashew (Anacardium occidentale L.). Ecophysiology of tropical crops. Itabuna: CEPLAC, 1975. v.2, p.1-26.

PARENTE, J.I.G., MACIEL, R.F.P., VALE, E.C. Cajueiro: aspectos econômicos e agronômicos. Recife : IPEANE, 1972. 52 p. (Circular, 19).

PARENTE, J.I.G. Estudos fenológicos do cajueiro (Anacardium occidentale L.) no litoral do Ceará. Fortaleza - CE, 1981. 48p. Dissertação (Mestrado em Agronomia) Curso de Pós-graduação em Fitotecnia, Universidade Federal do Ceará, 1981.

RICHARDS, L.A. Diagnosis and improvement of saline and alkaline soils. Washington : Department of Agriculture, 1954. $172 \mathrm{p}$.

UNIVERSIDADE FEDERAL DO CEARÁ. Dados meteorológicos. Fortaleza : Centro de Ciências Agrárias Estação Meteorológica, 1997. n.p. (Documentos, s.n.). 